\title{
Türkiye'de Ormancılık Sektöründe Meydana Gelen İş Kazalarının Değerlendirilmesi
}

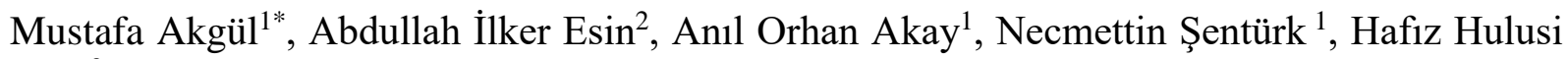 \\ Acar $^{3}$ \\ ${ }^{1}$ İstanbul Üniversitesi-Cerrahpaşa, Orman Fakültesi, Orman Mühendisliği Bölümü, 34473, İstanbul \\ 2 İstanbul Üniversitesi-Cerrahpaşa, Ormancıllk Meslek Yüksekokulu, Sulama Teknolojisi Programı, 34473, \\ İstanbul \\ ${ }^{3}$ İstanbul Yeni Yüzyıl Üniversitesi, Sağlık Bilimleri Fakültesi, İş Sağlığı ve Güvenliği Bölümü, 34010, İstanbul
}

\section{Öz}

Ormancılık sektöründe silvikültürel müdahaleler, orman ürünlerinin bölmeden çıkarılması gibi farklı çalışma koşulları içeren iş faaliyetleri olup, iş kazaları çevresel ve kişisel faktörlere bağlı olarak meydana gelebilmektedir. Ortaya konulan bu çalışmada, Türkiye'de ormancılık sektöründe 2013-2019 yılları arasında meydana gelen iş kazalarını çeşitli ölçütler esas alınarak Türkiye genelindeki iş kazaları açısından değerlendirmek ve ormancılıkta sektöründeki ekonomik faaliyet sınıflarına göre iş kazalarını değerlendirmek amaçlanmıştır. Bu kapsamda değerIendirme ölçütleri olarak kaza sıklık oranı (KSO), kaza frekansı (KF) ve kaza ağırlık oranı (KAO) kullanılmıştır. Ormancılık sektöründe iş kazaları ekonomik faaliyet sınıfları açısından incelendiğinde ise, yıllar itibariyle ölümlü olmayan iş kazalarına göre "ormancılık için destekleyici faaliyetler ekonomik faaliyeti”nin KS, KF ve KAO ölçütleri açısından diğer ormancılık ekonomik faaliyetleriyle kıyaslandığında en yüksek değere sahip olduğu belirlenmiştir. Ulaşılan bulgular genel olarak değerlendirildiğinde, ormancılık sektörünün Türkiye genelindeki iş kazaları açısından durumu belirlenerek, sektörün durumu ortaya konulmuştur.

Anahtar Kelimeler: İş güvenliği, kaza sıklık oranı, kaza frekansı, kaza ağırlık oranı, Türk ormancılık sektörü.

\section{Analysis of Occupational Accidents Occurred in The Forestry Sector in Turkey}

\begin{abstract}
In the forestry sector, activities with different working conditions such as silvicultural studies and logging take place, and occupational accidents may occur depending on environmental and personal factors. In this study, it was aimed to evaluate the occupational accidents in the Turkish forestry sector comparing with occupational accidents across Turkey between 2013-2019. At the same time, it is aimed to evaluate occupational accidents according to economic activity classes in the forestry sector. In this context, incidence rate (IR), frequency rate (FR) and severity rate (SR) were used as evaluation criteria. When occupational accidents in the forestry sector are examined in terms of economic activity classes, it has been determined that the "supporting activities in forestry" have a higher value in terms of IR, FR and SR criteria than "silvicultural and other forestry activities", "logging activities" and "harvesting wild-grown products other than trees". When the findings are evaluated in general, cases of occupational accidents in the forestry sector have been put forward across Turkey.
\end{abstract}

Keywords: Occupational safety, accident incidence rate, accident frequency, accident weight rate, Turkish forestry sector. 


\section{Giriş}

İş kazalarının en önemli sonuçları ölüm, yaralanma veya kalıcı iş göremezliktir (Ceylan, 2015). Her yıl dünya genelinde değişik iş kollarında sayısız iş kazası meydana gelmekte ve bunların büyük bir çoğunluğu kalıcı hasarlara yol açmaktadır. Bu nedenle özellikle 2000'li yılların başından itibaren iş güvenliği ve iş sağlı̆̆ konuları, iş kazalarını önlemek ve/veya en aza indirmek için her sektörde en önemli unsurlardan biri haline gelmiştir.

İş kazalarına ait ilk yasal düzenlemeler ve çalışmalar sanayi devrimi ve işçi sayısının artmasıyla başlamıştır. Osmanlı döneminde yapılmış ilk düzenleme ise 1867 yılında Ereğli maden ocaklarında çalışan işçiler için ortaya konulan Dilaver Paşa Nizamnamesi' dir (Polatoğlu ve Sincar, 1999; Yüksel, 2017). Cumhuriyet döneminde ise iş güvenliği ve işçi sağlığına dair ilk yasalar 1920’li yıllarda çıkarılmıştır (Özdemir, 2019).

Uluslararası Çalışma Örgütü’nün (International Labor Organization) (ILO) tahminlerine göre dünya genelinde her yıl 2,78 milyon ölümlü iş kazası, 374 milyon civarında da ölümlü olmayan iş kazası ile ortalama dört gün ve daha fazla raporla sonuçlanan iş kazası meydana gelmektedir (ILO, 2020a). ILO verilerine göre, küresel işgücünün \%0,4'ü (13,7 milyon kişi) tarım ve ormancılık alanında çalışmaktadır (ILO, 2020b). 2015 yılı Eurostat verilerine göre ise Avrupa Birliği'ne bağlı ülkelerde ormancılık ve odun üretimi sektöründe toplamda yaklaşık 500.000 kişi çalışmaktadır (Eurostat, 2020).

Ormancılık sektörü, iş kazası açısından en tehlikeli sektörlerden biri olarak değerlendirilmektedir (Klun ve Medved, 2007; Rhee vd., 2013). Ormancılık sektörü hem çevresel hem de kişisel faktörlerden etkilenmektedir (Lilley vd., 2002). Diğer sektörlerden farklı olarak ormancılık sektöründe çalışan işçilerin çoğu açık alanlarda çalışmakta, yoğun bitki örtüsünden, değişken ve zorlu arazi yapılarından, ekstrem hava şartlarından doğrudan etkilenmektedir. Söz konusu tehlikeli ve ekstrem koşullar altında oluşabilecek kişisel hatalar ise iş kazası riskini artıran en önemli faktörlerden birisidir.

Ormancılıkta meydana gelen iş kazaları üzerine farklı çalışmalar yapılmıştır. Bu çalışmalardan bir kısmı, bölmeden çıkarma sırasında meydana gelen iş kazaları (Enez ve vd., 2014; Gümüş vd., 2019), motorlu testere kullanımı sırasındaki iş kazaları (Bentley vd., 2005; Cividino vd., 2012; Robb ve Cocking, 2014), hava hatlarının kullanımı sırasındaki iş kazaları (Allman, 2017; Tsioras vd., 2011), orman işçilerindeki iş sağlığı (Acar ve Şentürk, 1999) vb konular üzerinde yoğunlaşmıştır.

İşgücü değerlendirme ve sınıflandırmasında yaygın olarak iki sınıflandırma sistemi kullanılmaktadır. Bunlar ILO ve NACE'ye (Nomenclature des Activités Économiques dans la Communauté Européenne) ait sınıflandırmalardır. Türkiye'de de Sosyal Güvenlik Kurumu (SGK) tarafından yayınlanan iş kazası istatistiklerinde NACE ekonomik faaliyet kodları dikkate alınmaktadır.

Bu bağlamda, çalışmada 2013-2019 yılları arasında Türkiye genelinde ve ormancılık sektöründe meydana gelen iş kazaları kaza sıklık oranı, kaza frekansı ve kaza ağırlık oranı ölçütleri açısından iki farklı amaçla değerlendirilmiştir. Birincisi, ormancılık sektöründeki meydana gelen iş kazalarını genel olarak Türkiye geneli iş kazalarına kıyasla değerlendirmek, ikincisi ise ormancılık sektöründe meydana gelen iş kazalarını kendi ekonomik faaliyet sınıfları açısından değerlendirmektir.

\section{Materyal ve Metot}

Türkiye'de ormancılık sektörüne ait iş kazaları verileri SGK tarafından yayınlanan istatistik yıllıklarından elde edilmektedir. Bu bağlamda, 2013-2019 yılları arasında Türkiye genelinde ve ormancılık sektöründe meydana gelen iş kazalarına ait veriler irdelenmiştir. Çalışmada ayrıca, ormancılık sektörü NACE Rev.2'ye göre 02.1 Orman yetiştirme (silvikültür) ve diğer ormancılık faaliyetleri; 02.2 Tomrukçuluk; 02.3 A ̆gaç dişındaki yabani olarak yetişen ürünlerin toplanması; 02.4 Ormancllı için destekleyici faaliyetler olmak üzere dört grup karşılaştırmalı olarak da incelenmiştir (SGK, 2019).

\subsection{Ormancılık Sektörü ve Türkiye geneli iş kazası verileri}

Ormancılık sektörü ve Türkiye geneline ait 2013-2019 yılları arasındaki iş kazaları ile iş göremezlik sürelerine ait veriler Tablo 1'de verilmiştir. 2013-2019 yılları arasındaki ortalama değerlere bakıldığında; ormancılık sektöründe çalışan işçi sayısının, Türkiye genelinde çalışan toplam işçi sayısının yaklaşık 1/300'üne tekabül ettiği görülmektedir. Ormancılık sektöründe meydana gelen ölümlü olmayan iş kazaları ortalaması (373) ise Türkiye genelindeki ölümlü olmayan iş kazası sayısının (307.711) yaklaşık 1/800'üne; ölümlü iş kazası ortalaması ise (7) Türkiye geneli ortalamasının 1/220'sine tekabül etmektedir (Tablo 1). 
Tablo 1. Ormancılık sektörü ve Türkiye geneli işçi sayıları, kaza verileri ve iş göremezlik süreleri (2013-2019).

\begin{tabular}{|c|c|c|c|c|c|c|c|c|c|c|c|c|c|c|}
\hline \multirow[b]{3}{*}{ YII } & \multirow{2}{*}{\multicolumn{2}{|c|}{ İşçi sayısı }} & \multicolumn{6}{|c|}{ İş kazası sayısı } & \multirow{2}{*}{\multicolumn{2}{|c|}{$\begin{array}{l}\text { Prim tahakkuk } \\
\text { Gün sayısı } \\
\end{array}$}} & \multirow{2}{*}{\multicolumn{2}{|c|}{$\begin{array}{l}\text { Geçici İş } \\
\text { Göremezlik süresi }\end{array}$}} & \multirow{2}{*}{\multicolumn{2}{|c|}{$\begin{array}{l}\text { Sürekli İş göremezlik } \\
\text { Derecesi toplamı }\end{array}$}} \\
\hline & & & \multicolumn{3}{|c|}{ Ormancılık Sektörü } & \multicolumn{3}{|c|}{ Türkiye Geneli } & & & & & & \\
\hline & $\begin{array}{l}\text { Ormancillk } \\
\text { Sektörü }\end{array}$ & $\begin{array}{l}\text { Türkiye } \\
\text { Geneli }\end{array}$ & $\begin{array}{l}\text { Ölümlü } \\
\text { Olmayan }\end{array}$ & Ölümlü & Toplam & $\begin{array}{l}\begin{array}{l}\text { Ölümlü } \\
\text { Olmayan }\end{array} \\
\end{array}$ & Ölümlü & Toplam & $\begin{array}{l}\text { Ormancillk } \\
\text { Sektörü }\end{array}$ & $\begin{array}{l}\text { Türkiye } \\
\text { Geneli }\end{array}$ & $\begin{array}{l}\text { Ormancillk } \\
\text { Sektörü }\end{array}$ & $\begin{array}{l}\text { Türkiye } \\
\text { Geneli }\end{array}$ & $\begin{array}{l}\begin{array}{l}\text { Ormancillk } \\
\text { Sektörü }\end{array} \\
\end{array}$ & $\begin{array}{l}\text { Türkiye } \\
\text { Geneli }\end{array}$ \\
\hline 2013 & 33.696 & 12.484 .113 & 192 & 7 & 199 & 191.389 & 1.360 & 192.749 & 10.984 .926 & 4.069 .831 .784 & 4.226 & 2.357 .505 & 64 & 52.825 \\
\hline 2014 & 37.646 & 13.240 .122 & 202 & 5 & 207 & 221.366 & 1.626 & 222.992 & 12.079 .672 & 4.248.428.182 & 2.699 & 2.065 .962 & 30 & 42.857 \\
\hline 2015 & 97.820 & 13.999.398 & 434 & 7 & 441 & 241.547 & 1.252 & 242.799 & 31.178 .611 & 4.462.091.444 & 8.413 & 2.992 .070 & 121 & 103.833 \\
\hline 2016 & 34.666 & 13.775 .188 & 345 & 7 & 352 & 286.068 & 1.405 & 287.473 & 11.386 .151 & 4.524 .501 .578 & 6.343 & 3.453 .702 & 393 & 134.403 \\
\hline 2017 & 39.705 & 14.477.817 & 447 & 8 & 455 & 359.866 & 1.636 & 361.502 & 15.188 .419 & 5.538.222.988 & 6.804 & 3.997 .742 & 825 & 253.005 \\
\hline 2018 & 34.620 & 14.229 .170 & 486 & 9 & 495 & 431.276 & 1.542 & 432.818 & 14.692 .537 & 6.038 .781 .316 & 4.905 & 2.488 .401 & 1.285 & 484.902 \\
\hline 2019 & 27.025 & 14.314 .313 & 508 & 8 & 516 & 422.463 & 1.147 & 423.610 & 9.264 .282 & 4.907.005.930 & 5.256 & 3.624 .934 & 487 & 123.623 \\
\hline Ort. & 43.597 & 13.788 .589 & 373 & 7 & 381 & 307.711 & 1.424 & 309.135 & 14.967 .800 & 4.826 .980 .460 & 5.521 & 2.997.188 & 458 & 170.778 \\
\hline
\end{tabular}

Ormancılık sektörü kendi içerisinde NACE kod sınıflarına göre detaylı olarak incelendiğinde; 2013-2019 yılları arasında yıllık ortalama ölümlü olmayan kaza sayısının en düşük olduğu faaliyet kolu Ağaç Dışındaki Yabani Olarak Yetişen Ürünlerin Toplanması (yıllık ortalama:10) faaliyeti tüm ormancılık sektörü ortalamasının \%3’ünü, en yüksek vaka sayısının görüldügü Ormancılık için Destekleyici Faaliyetler (yıllık ortalama:190) ise yaklaşık \%51'ni oluşturmaktadır. Silvikültür ve diğer ormancılık faaliyetleri kapsamında karşıllaşılan kaza sayısı ortalaması (118) tüm ormancılık faaliyetlerinin \%31’ine, Tomrukçuluk işleri kapsamında karşılaşılan kaza sayısı ortalaması ise (54) \%15'ine tekabül etmektedir (Tablo 2).

Tablo 2. Ölümlü olmayan iş kazası geçirenlerin ekonomik faaliyetlere göre dağılımı.

\begin{tabular}{|c|c|c|c|c|c|c|c|c|c|c|c|c|c|c|c|c|}
\hline & Erkek & & & & & & & Kadın & & & & & To & am & & \\
\hline $\begin{array}{l}\text { Ekonomik } \\
\text { Faaliyet } \\
\text { Sinıflaması } \\
\text { (NACE Rev. 2)* } \\
\end{array}$ & $\begin{array}{l}\text { Kaza } \\
\text { günüi } \\
\text { (çalışır) }\end{array}$ & $\begin{array}{l}\text { Kaza günü } \\
\text { (işgöremez) }\end{array}$ & 2 & 3 & 4 & $5+^{(1)}$ & $\begin{array}{l}\text { Kaza } \\
\text { günü } \\
\text { (çalışır) }\end{array}$ & $\begin{array}{l}\text { Kaza günü } \\
\text { (işgöremez) }\end{array}$ & 2 & 3 & 4 & $5+^{(1)}$ & Erkek & Kadın & Toplam & YIL \\
\hline 02.1 & 29 & 0 & 1 & 4 & 0 & 24 & 58 & 2 & 0 & 0 & 0 & 0 & 0 & 2 & 60 & 2013 \\
\hline 02.2 & 15 & 1 & 2 & 3 & 0 & 24 & 45 & 0 & 0 & 0 & 0 & 0 & 0 & 0 & 45 & \\
\hline 02.3 & 0 & 0 & 0 & 0 & 0 & 1 & 1 & 3 & 0 & 0 & 0 & 3 & 3 & 6 & 7 & \\
\hline 02.4 & 45 & 0 & 2 & 2 & 0 & 26 & 75 & 2 & 0 & 0 & 0 & 3 & 3 & 5 & 80 & \\
\hline Ormancılık Toplamı & 89 & 1 & 5 & 9 & 0 & 75 & 179 & 7 & 0 & 0 & 0 & 6 & 179 & 13 & 192 & \\
\hline 02.1 & 27 & 1 & 1 & 4 & 0 & 14 & 3 & 0 & 0 & 0 & 0 & 0 & 47 & 3 & 50 & 2014 \\
\hline 02.2 & 21 & 0 & 1 & 1 & 0 & 15 & 1 & 0 & 0 & 0 & 0 & 0 & 38 & 1 & 39 & \\
\hline 02.3 & 2 & 1 & 1 & 1 & 1 & 6 & 2 & 0 & 0 & 0 & 0 & 1 & 12 & 3 & 15 & \\
\hline 02.4 & 64 & 0 & 1 & 1 & 1 & 26 & 4 & 0 & 0 & 0 & 1 & 0 & 93 & 5 & 98 & \\
\hline Ormancılık Toplamı & 114 & 2 & 4 & 7 & 2 & 61 & 10 & 0 & 0 & 0 & 1 & 1 & 190 & 12 & 202 & \\
\hline 02.1 & 62 & 2 & 5 & 10 & 1 & 42 & 32 & 1 & 1 & 3 & 0 & 30 & 122 & 67 & 189 & 2015 \\
\hline 02.2 & 17 & 2 & 1 & 2 & 1 & 15 & 0 & 0 & 0 & 0 & 0 & 0 & 38 & 0 & 38 & \\
\hline 02.3 & 1 & 2 & 0 & 1 & 0 & 5 & 1 & 0 & 0 & 0 & 0 & 1 & 9 & 2 & 11 & \\
\hline 02.4 & 72 & 0 & 2 & 4 & 1 & 72 & 33 & 0 & 1 & 2 & 0 & 9 & 151 & 45 & 196 & \\
\hline Ormancılık Toplamı & 152 & 6 & 8 & 17 & 3 & 134 & 66 & 1 & 2 & 5 & 0 & 40 & 320 & 114 & 434 & \\
\hline 02.1 & 51 & 0 & 5 & 3 & 3 & 23 & 13 & 1 & 1 & 3 & 0 & 8 & 85 & 26 & 111 & 2016 \\
\hline 02.2 & 32 & 2 & 2 & 0 & 0 & 17 & 1 & 0 & 0 & 1 & 0 & 0 & 53 & 2 & 55 & \\
\hline 02.3 & 1 & 0 & 0 & 0 & 0 & 1 & 0 & 0 & 0 & 0 & 0 & 0 & 2 & 0 & 2 & \\
\hline 02.4 & 84 & 1 & 9 & 5 & 2 & 65 & 7 & 0 & 0 & 0 & 0 & 4 & 166 & 11 & 177 & \\
\hline Ormancılık Toplamı & 168 & 3 & 16 & 8 & 5 & 106 & 21 & 1 & 1 & 4 & 0 & 12 & 306 & 39 & 345 & \\
\hline 02.1 & 51 & 0 & 4 & 5 & 1 & 39 & 26 & 0 & 0 & 0 & 0 & 4 & 100 & 30 & 130 & 2017 \\
\hline 02.2 & 41 & 0 & 2 & 4 & 1 & 24 & 1 & 0 & 0 & 0 & 0 & 0 & 72 & 1 & 73 & \\
\hline 02.3 & 3 & 1 & 1 & 0 & 0 & 1 & 3 & 0 & 0 & 0 & 0 & 0 & 6 & 3 & 9 & \\
\hline 02.4 & 120 & 1 & 3 & 6 & 3 & 78 & 15 & 0 & 0 & 2 & 0 & 7 & 211 & 24 & 235 & \\
\hline Ormancılık Toplamı & 215 & 2 & 10 & 15 & 5 & 142 & 45 & 0 & 0 & 2 & 0 & 11 & 389 & 58 & 447 & \\
\hline 02.1 & 109 & 0 & 1 & 0 & 0 & 10 & 43 & 0 & 0 & 0 & 0 & 2 & 120 & 45 & 165 & 2018 \\
\hline 02.2 & 54 & 0 & 3 & 0 & 0 & 4 & 0 & 0 & 0 & 0 & 0 & 0 & 61 & 0 & 61 & \\
\hline 02.3 & 0 & 0 & 0 & 0 & 0 & 0 & 4 & 0 & 0 & 0 & 0 & 1 & 0 & 5 & 5 & \\
\hline 02.4 & 186 & 1 & 1 & 1 & 0 & 47 & 15 & 1 & 0 & 0 & 0 & 3 & 236 & 19 & 255 & \\
\hline Ormancılık Toplamı & 349 & 1 & 5 & 1 & 0 & 61 & 62 & 1 & 0 & 0 & 0 & 6 & 417 & 69 & 486 & \\
\hline 02.1 & 53 & 2 & 2 & 7 & 3 & 30 & 17 & 0 & 1 & 6 & 0 & 6 & 97 & 30 & 127 & 2019 \\
\hline 02.2 & 47 & 2 & 4 & 7 & 0 & 12 & 0 & 0 & 0 & 0 & 0 & 0 & 72 & 0 & 72 & \\
\hline 02.3 & 8 & 0 & 0 & 3 & 0 & 2 & 5 & 0 & 1 & 0 & 0 & 2 & 13 & 8 & 21 & \\
\hline 02.4 & 179 & 5 & 8 & 7 & 3 & 76 & 8 & 0 & 0 & 0 & 0 & 2 & 278 & 10 & 288 & \\
\hline Ormancılık Toplamı & 287 & 9 & 14 & 24 & 6 & 120 & 30 & 0 & 2 & 6 & 0 & 10 & 460 & 48 & 508 & \\
\hline
\end{tabular}

02.1: Orman yetiştirme (silvikültür) ve diğer ormancılık faaliyetleri

02.2: Tomrukçuluk

02.3: Ağaç dışındaki yabani olarak yetişen ürünlerin toplanması

02.4: Ormancılık için destekleyici faaliyetler 
2013-2019 yılları arasında ormancılık sektörünün alt ekonomik faaliyet gruplarında meydana gelen ölümlü iş kazaları değerlendirildiğinde, ormancılık genelinde meydana gelen toplam ölümlü kaza sayılarının \%54'ü Ormancılık için Destekleyici Faaliyetlerden (28), \%24'ü Tomrukçuluk işlerinden (12), \%21'si Silvikültür ve Diğer Ormancılık Faaliyetlerinden (10), ve \%2'si ise Ağaç Dışındaki Yabani Olarak Yetişen Ürünlerin Toplanmasından meydana gelmiştir (1) (Tablo 3).

Tablo 3. Ölümlü iş kazalarının ekonomik faaliyetlere göre dağılımı.

\begin{tabular}{|c|c|c|c|c|}
\hline \multirow{2}{*}{$\begin{array}{l}\text { Ekonomik Faaliyet Sinıflaması } \\
\text { (NACE Rev. 2)* }^{\text {(NAC }}\end{array}$} & \multicolumn{3}{|c|}{ İş kazası sonucu ölen sigortalı sayısı ${ }^{(1)}$} & \multirow[t]{2}{*}{ YIL } \\
\hline & Erkek & Kadın & Toplam & \\
\hline 02.1 & 2 & 0 & 2 & 2013 \\
\hline 02.2 & 3 & 0 & 3 & \\
\hline 02.3 & 0 & 1 & 1 & \\
\hline 02.4 & 1 & 0 & 1 & \\
\hline Ormancılık Toplamı & 6 & 1 & 7 & \\
\hline 02.1 & 1 & 0 & 1 & 2014 \\
\hline 02.2 & 1 & 0 & 1 & \\
\hline 02.3 & 0 & 0 & 0 & \\
\hline 02.4 & 3 & 0 & 3 & \\
\hline Ormancılık Toplamı & 5 & 0 & 5 & \\
\hline 02.1 & 2 & 1 & 3 & 2015 \\
\hline 02.2 & 2 & 0 & 2 & \\
\hline 02.3 & 0 & 0 & 0 & \\
\hline 02.4 & 2 & 0 & 2 & \\
\hline Ormancılık Toplamı & 6 & 1 & 7 & \\
\hline 02.1 & 1 & 0 & 1 & 2016 \\
\hline 02.2 & 2 & 0 & 2 & \\
\hline 02.3 & 0 & 0 & 0 & \\
\hline 02.4 & 4 & 0 & 4 & \\
\hline Ormancılık Toplamı & 7 & 0 & 7 & \\
\hline 02.1 & 0 & 0 & 0 & 2017 \\
\hline 02.2 & 2 & 0 & 2 & \\
\hline 02.3 & 0 & 0 & 0 & \\
\hline 02.4 & 6 & 0 & 6 & \\
\hline Ormancılık Toplamı & 8 & 0 & 8 & \\
\hline 02.1 & 4 & 0 & 4 & 2018 \\
\hline 02.2 & 1 & 0 & 1 & \\
\hline 02.3 & 0 & 0 & 0 & \\
\hline 02.4 & 4 & 0 & 4 & \\
\hline Ormancılık Toplamı & 9 & 0 & 9 & \\
\hline 02.1 & 0 & 0 & 0 & 2019 \\
\hline 02.2 & 1 & 0 & 1 & \\
\hline 02.3 & 0 & 0 & 0 & \\
\hline 02.4 & 8 & 0 & 8 & \\
\hline Ormancılık Toplamı & 9 & 0 & 9 & \\
\hline
\end{tabular}

* 02.1: Orman yetiștirme (silvikültür) ve diğer ormancılık faaliyetleri

02.2: Tomrukçuluk

02.3: Ağaç dışındaki yabani olarak yetişen ürünlerin toplanması

02.4: Ormancılık için destekleyici faaliyetler

\section{2. İş kazası değerlendirme ölçütleri}

Sektörler içindeki ve/veya sektörler arasındaki iş kazalarının sağlıklı bir şekilde değerlendirilebilmesi/karşılaştırılabilmesi için sadece kaza sayılarının esas alınması yeterli olmamaktadır. Sektörlerde çalışan işçi sayılarındaki ve/veya çalışma sürelerindeki farklılıklar, iş güvenliği konusundaki başarı oranının belirlenmesinde, bazı karşılaştırma ölçütlerinin kullanılmasını gerektirmektedir. Bu çalışmada dikkate alınan ölçütler aşağıda sıralanmıştır.

\section{Kaza sıklık oranı (KSO)}

Bir çalışma yılı içerisinde 100.000 kişi başına düşen iş kazası sayısı olarak tanımlanmaktadır (Denklem 1). Bu oran farklı literatür çalışmalarında 1.000 (Müngen, 1993), 10.000, 100.000 (Güllüoğlu ve Taçkın 2018; Güllüoğlu ve Güllüoğlu, 2019) ve 1.000.000 (Ceylan, 2012; Ceylan, 2014) işçi esas alınarak da hesaplanmıştır. 
$K S O=\frac{K S \times 10^{5}}{\text { Ç่S }}$

KS = Kaza sayısı,

ÇİS =Çalışan işçi sayısı

\section{Kaza frekansı (veya kaza tekrarlama oranı) (KF, KTO)}

Bir takvim yılında çalışılan 1.000 .000 iş saatine karşılık, kaç iş kazasının gerçekleştiğini gösterir (Denklem 2) (SGK, 2019).

$K F=\frac{K S \times 10^{6}}{T C S S}$

KS= Kaza sayısı

TÇS=Toplam çalışma saati (her gün için 8 saatlik tam çalışma ile çarpılarak bulunur)

TÇS $=(P T E G S * 8)$

PTEGS = Prim tahakkuk eden gün sayısı

\section{Kaza ağırık oranı (KAO)}

“Kaza Şiddet Oranı” olarak da adlandırılan bu ölçüt, iş kazasının sayısal durumunu değil, sebep olduğu iş günü kaybı açısından önemini saptamak için önemlidir (Müngen, 1993). Bir takvim yılında çalışılan 1.000.000 saatte kaç iş gününün iş kazası nedeniyle kaybedildiğini gösterir (Denklem 3-4) (SGK, 2019).

$K A O=\frac{T G K \times 10^{6}}{T C ̧ S}$

$T G K=(G \dot{I} G S)+(S \dot{I} G D T * 75)+(\ddot{O} V S * 7500)$

$T G K=$ Toplam gün kaybl

GIGS = Geçici iş göremezlik [1] süresi

SIGDT = Sürekli iş göremezlik [2] dereceleri toplamı

ÖVS = Ölümlü vaka sayısı

[1] İş göremezlik: İş kazası nedeniyle sigortalının iş göremediği süredir.

[2] Sürekli iş göremezlik: İş kazası sonucu oluşan hastalık ve engeli nedeniyle kurumca yetkilendirilen sağlık hizmeti sunucularının sağlık kurulları tarafından verilen raporlara istinaden kurum sağlık kurulunca meslekte kazanma gücünün en az \%10 oranında azalmış olma durumunu ifade eder (5510 sayılı kanunun 19. maddesi).

\section{Bulgular ve Tartışma}

\subsection{Türkiye genelinin ve ormancılık sektörünün iş kazası ölçütlerine göre değerlendirilmesi}

Çalışmada, 2013-2019 yılları arası Türkiye genelindeki tüm sektörler ve ormancılık sektörü geneli meydana gelen iş kazaları KSO, KF ve KAO ölçütleri açısından karşılaştırılmıştır. Kaza Sıklık Oranları açısından 2013-2019 yılları arasında Türkiye geneli ile ormancılık sektöründeki toplam ve ölümlü olmayan KSO'lar yıllar itibariyle artış eğiliminde bulunmaktadır (Şekil 1). Türkiye genelinde KSO, ormancılık sektörünün yaklaşık 2,5 katıdır. Ölümlü iş kaza sayılarına bağlı olarak hesaplanan KSO'lar dikkate alındığında ise ormancılık sektörü ortalamasının Türkiye ortalamasından yaklaşık 1,5 katı olduğu görülmektedir (Tablo 4).

Toplam ve ölümlü olmayan Kaza Frekansları açısından bakıldığında KSO’larda olduğu gibi hem Türkiye genelinde hem de ormancılık sektöründe 2013-2019 yıllarında birbirine paralel bir artış eğilimi gözlemlenmektedir (Şekil 1). Toplam KF değerleri dikkate alındığında Türkiye geneline ait yedi yıllık ortalama KF değerinin $(7,39)$ ormancılık sektörünün $(3,00)$ yaklaşık 2,5 katı olduğu görülmektedir. Ölümlü kaza sayısına bağlı olarak hesaplanan KF değerleri açısından ise 2015 yılı hariç tüm yıllarda ormancılık sektörü KF değerleri Türkiye geneli KF değerlerinden yüksektir. Ormancılık sektöründeki ölümlü KF değerleri ortalamasının $(0,06)$ ise Türkiye geneli ortalamasının $(0,04)$ 1,5 katı olduğu görülmektedir (Tablo 4).

Bulgular, Kaza Ağırlık Oranları açısından değerlendirildiğinde; ormancılık sektörü ortalama KAO değeri 
$(814,05)$ ile Türkiye ortalaması $(784,17)$ değerinin birbirine yakın olduğu görülmektedir (Tablo 4). Robert vd., (2015) tarafından yapılan bir çalışmada Avrupa genelinde ormancılık ve ziraat sektörlerinde meydana gelen ölümlü iş kazası sayılarının diğer sektörlerden yüksek olduğu vurgulanmıştır. Aynı çalışmada, sadece inşaat sektöründe meydana gelen ölümlü iş kazalarının ise ormancılık sektöründen nispeten yüksek olduğu belirtilmiştir. Avusturya'da yapılan diğer bir çalışmada yine tarım ve ormancılık sektöründe meydana gelen ölümlü iş kazası sayılarının ve KAO oranının diğer sektörlere göre operatör eğitimi ve teknolojik ekipman kullanım oranlarının yüksek olmasına rağmen ülke genelinden daha yüksek olduğu görülmüştür (Kogler vd., 2015).

Tablo 4. 2013-2019 yılları arası Türkiye geneli ve ormancılık sektöründe meydana gelen iş kazalarına ait ölçütler.

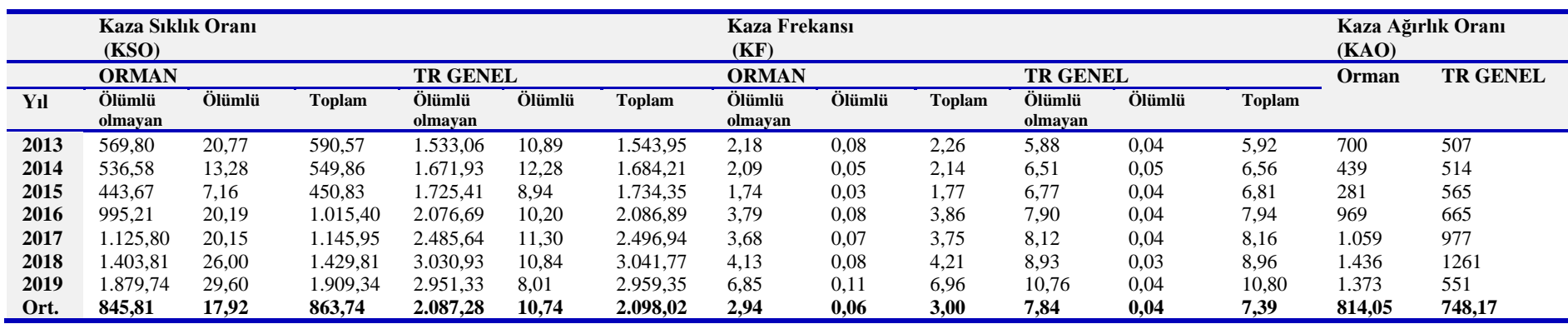

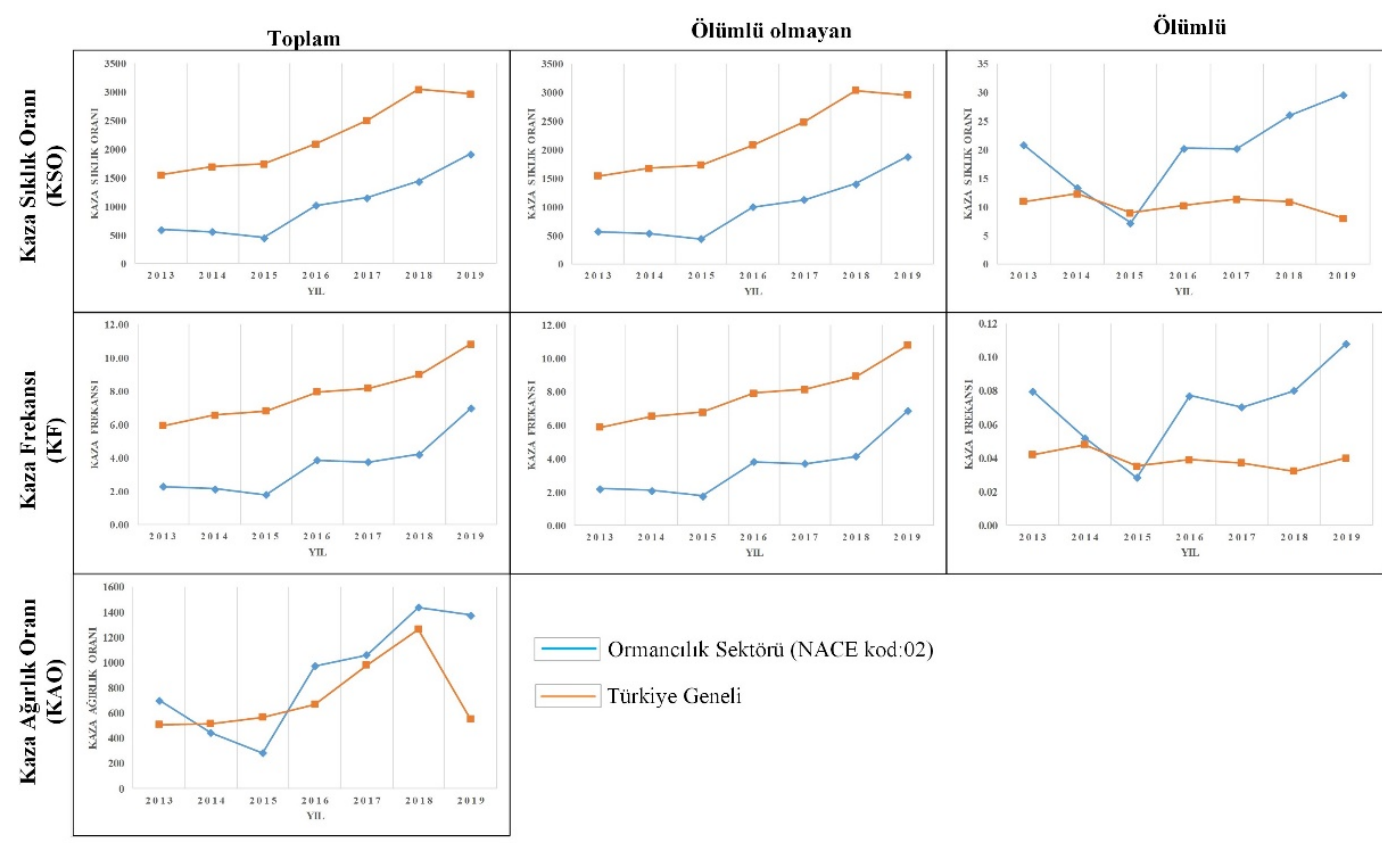

Şekil 1. 2013-2019 yılları arası Türkiye geneli ve ormancılık sektöründe meydana gelen iş kazalarına ait ölçütler.

\subsection{Ormancılık sektöründe faaliyet gruplarının iş kazası ölçütlerine göre değerlendirilmesi}

Ormancılık sektörü NACE ekonomik faaliyet gruplarına göre kendi içerisinde değerlendirildiğinde; ölümlü olmayan iş kazaları dikkate alındığında 02.4 kodlu Ormancılık için destekleyici faktörlerin KSO, KF ve KAO ölçütleri açısından diğer ormancılık alt faaliyetlerine göre en yükssek değerlere sahip olduğu görülmektedir. İkinci sırada 02.1 kodlu Silvikültürel ve diğer ormancılık faaliyetleri, üçüncü sırada ise 02.02 kodlu Tomrukçuluk faaliyetleri yer almaktadır. En düşük değerlerin ise 02.03 kodlu Ağaç dışındaki yabani olarak yetişen ürünlerin toplanması kaleminde olduğu görülmektedir (Şekil 2) (Tablo 5).

2013-2019 yılları arası ortalama ölümlü olmayan, ölümlü ve toplam KSO, KF ve KAO değerleri dikkate alındığında, en yüksek oranların 02.4 kodlu Ormancılık için destekleyici faaliyetler sınıfında olduğu, en düşük oranların ise 02.3 kodlu Ağaç dışındaki yabani olarak yetişen ürünlerin toplanması sınıfında olduğu görülmüştür (Şekil 2) (Tablo 5). 
Tablo 5. 2013-2019 yılları arası ormancılık sektöründe meydana gelen iş kazalarına ait ölçütler.

\begin{tabular}{|c|c|c|c|c|c|c|c|c|}
\hline \multirow[b]{2}{*}{ Yil } & \multirow[b]{2}{*}{$\begin{array}{l}\text { NACE Ekonomik } \\
\text { faaliyetlere göre } \\
\text { sinıflandırma } \\
\text { kodları } \\
\text { (NACE Rev.2) * }\end{array}$} & \multicolumn{2}{|c|}{ Ölümlü olmayan } & \multicolumn{2}{|l|}{ Ölümlü } & \multicolumn{3}{|c|}{ Toplam (ölümlü olmayan + ölümlü) } \\
\hline & & $\begin{array}{l}\text { Kaza Sıklık } \\
\text { Oranı } \\
\text { (KSO) }\end{array}$ & $\begin{array}{l}\text { Kaza Frekansı } \\
\text { (KF) }\end{array}$ & $\begin{array}{l}\text { Kaza } \\
\text { Sıklık } \\
\text { Oranı } \\
\text { (KSO) }\end{array}$ & $\begin{array}{l}\text { Kaza } \\
\text { Frekansı } \\
\text { (KF) }\end{array}$ & $\begin{array}{l}\text { Kaza } \\
\text { Sıklık } \\
\text { Oranı } \\
\text { (KSO) }\end{array}$ & $\begin{array}{l}\text { Kaza } \\
\text { Frekansı } \\
\text { (KF) }\end{array}$ & $\begin{array}{l}\text { Kaza } \\
\text { Ağırlık } \\
\text { Oranı } \\
\text { (KAO) }\end{array}$ \\
\hline \multirow[t]{5}{*}{2013} & 02.1 & 178,06 & 0,68 & 5,94 & 0,02 & 184,00 & 0,71 & 218,03 \\
\hline & 02.2 & 133,55 & 0,51 & 8,90 & 0,03 & 142,45 & 0,55 & 168,80 \\
\hline & 02.3 & 20,77 & 0,08 & 2,97 & 0,01 & 23,74 & 0,09 & 28,13 \\
\hline & 02.4 & 237,42 & 0,91 & 2,97 & 0,01 & 240,38 & 0,92 & 284,85 \\
\hline & Ormancılık Toplam & 569,80 & 2,18 & 20,77 & 0,08 & 590,57 & 2,26 & 699,82 \\
\hline \multirow[t]{5}{*}{2014} & 02.1 & 132,82 & 0,52 & 2,66 & 0,01 & 135,47 & 0,53 & 108,25 \\
\hline & 02.2 & 103,60 & 0,40 & 2,66 & 0,01 & 106,25 & 0,41 & 84,91 \\
\hline & 02.3 & 39,84 & 0,16 & 0,00 & 0,00 & 39,84 & 0,16 & 31,84 \\
\hline & 02.4 & 260,32 & 1,01 & 7,97 & 0,03 & 268,29 & 1,05 & 214,39 \\
\hline & Ormancılık Toplam & 536,58 & 2,09 & 13,28 & 0,05 & 549,86 & 2,14 & 439,38 \\
\hline \multirow[t]{5}{*}{2015} & 02.1 & 193,21 & 0,76 & 3,07 & 0,01 & 196,28 & 0,77 & 122,16 \\
\hline & 02.2 & 38,85 & 0,15 & 2,04 & 0,01 & 40,89 & 0,16 & 25,45 \\
\hline & 02.3 & 11,25 & 0,04 & 0,00 & 0,00 & 11,25 & 0,04 & 7,00 \\
\hline & 02.4 & 200,37 & 0,79 & 2,04 & 0,01 & 202,41 & 0,79 & 125,98 \\
\hline & Ormancılık Toplam & 443,67 & 1,74 & 7,16 & 0,03 & 450,83 & 1,77 & 280,59 \\
\hline \multirow[t]{5}{*}{2016} & 02.1 & 320,20 & 1,22 & 2,88 & 0,01 & 323,08 & 1,23 & 308,48 \\
\hline & 02.2 & 158,66 & 0,60 & 5,77 & 0,02 & 164,43 & 0,63 & 156,99 \\
\hline & 02.3 & 5,77 & 0,02 & 0,00 & 0,00 & 5,77 & 0,02 & 5,51 \\
\hline & 02.4 & 510,59 & 1,94 & 11,54 & 0,04 & 522,13 & 1,99 & 498,52 \\
\hline & Ormancılık Toplam & 995,21 & 3,79 & 20,19 & 0,08 & 1015,40 & 3,86 & 969,50 \\
\hline \multirow[t]{5}{*}{2017} & 02.1 & 327,41 & 1,07 & 0,00 & 0,00 & 327,41 & 1,07 & 370,31 \\
\hline & 02.2 & 183,86 & 0,60 & 5,04 & 0,02 & 188,89 & 0,62 & 213,64 \\
\hline & 02.3 & 22,67 & 0,07 & 0,00 & 0,00 & 22,67 & 0,07 & 25,64 \\
\hline & 02.4 & 591,87 & 1,93 & 15,11 & 0,05 & 606,98 & 1,98 & 686,49 \\
\hline & Ormancılık Toplam & 1125,80 & 3,68 & 20,15 & 0,07 & 1145,95 & 3,74 & 1296,07 \\
\hline \multirow[t]{5}{*}{2018} & 02.1 & 476,60 & 1,40 & 11,55 & 0,03 & 488,16 & 1,44 & 490,27 \\
\hline & 02.2 & 176,20 & 0,52 & 2,89 & 0,01 & 179,09 & 0,53 & 179,86 \\
\hline & 02.3 & 14,44 & 0,04 & 0,00 & 0,00 & 14,44 & 0,04 & 14,51 \\
\hline & 02.4 & 736,57 & 2,17 & 11,55 & 0,03 & 748,12 & 2,20 & 751,36 \\
\hline & Ormancılık Toplam & 1403,81 & 4,13 & 26,00 & 0,08 & 1429,81 & 4,21 & 1436,00 \\
\hline \multirow[t]{5}{*}{2019} & 02.1 & 469,94 & 1,71 & 0,00 & 0,00 & 469,94 & 1,71 & 337,27 \\
\hline & 02.2 & 266,42 & 0,97 & 3,70 & 0,01 & 270,12 & 0,98 & 193,87 \\
\hline & 02.3 & 77,71 & 0,28 & 0,00 & 0,00 & 77,71 & 0,28 & 55,77 \\
\hline & 02.4 & 1065,68 & 3,89 & 29,60 & 0,11 & 1095,28 & 3,99 & 786,09 \\
\hline & Ormancılık Toplam & 1879,74 & 6,85 & 33,30 & 0,12 & 1913,04 & 6,98 & 1373,00 \\
\hline $2013-2019$ & 02.1 & 299,75 & 1,05 & 3,73 & 0,01 & 303,48 & 1,07 & 279,25 \\
\hline \multirow[t]{3}{*}{ Ortalama } & 02.2 & 151,59 & 0,54 & 4,43 & 0,02 & 156,02 & 0,55 & 146,22 \\
\hline & 02.3 & 27,49 & 0,10 & 0,42 & 0,00 & 27,92 & 0,10 & 24,06 \\
\hline & 02.4 & 422,86 & 1.46 & 8,53 & 0,03 & 431,39 & 1,49 & 426,93 \\
\hline
\end{tabular}

* 02.1: Orman yetiștirme (silvikültür) ve diğer ormancillk faaliyetleri

02.2: Tomrukçuluk

02.3: Ağaç dişındaki yabani olarak yetișen ürünlerin toplanması

02.4: Ormanc1lik için destekleyici faaliyetler 


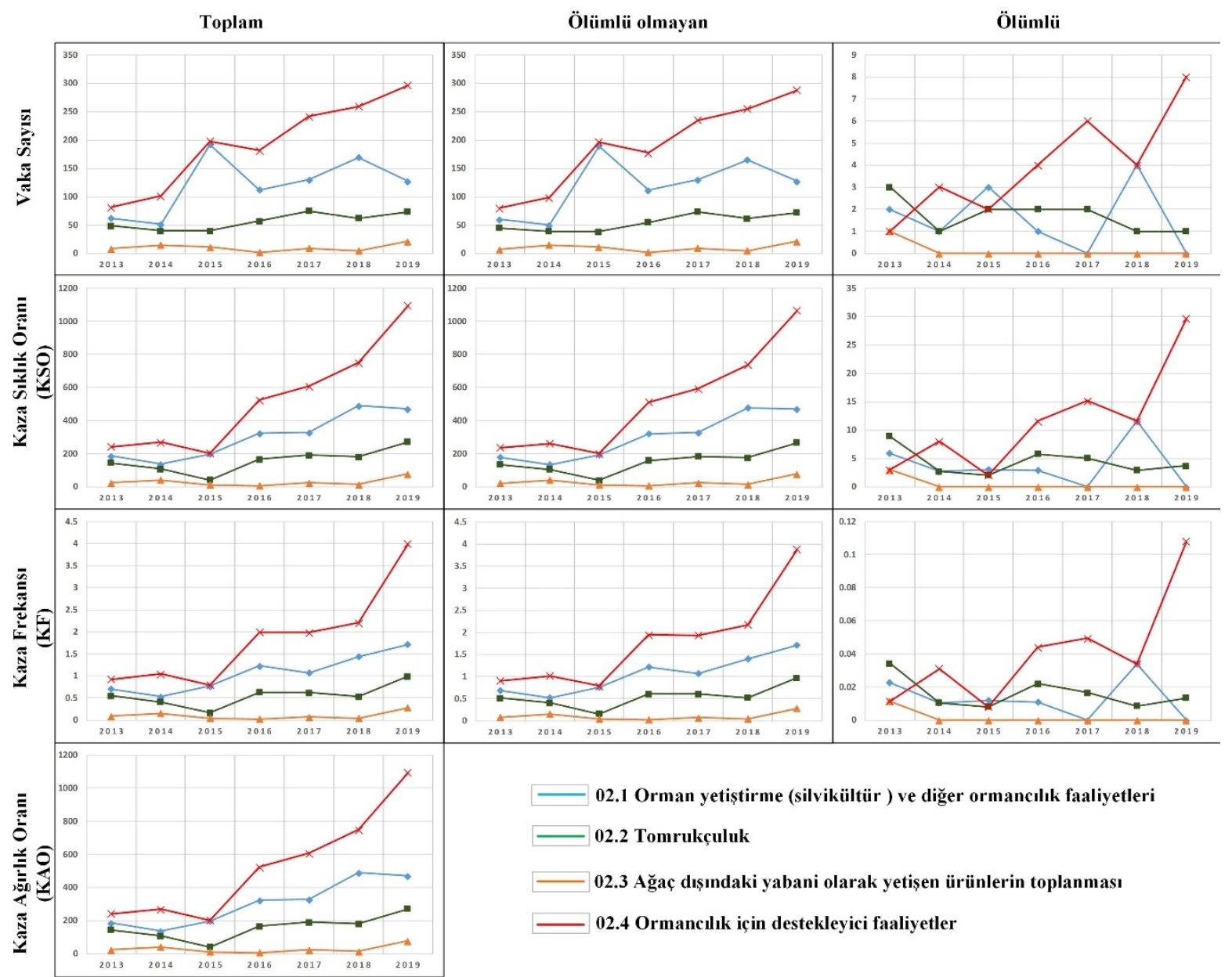

Şekil 2. 2013-2019 yılları arası ormancılık sektöründe meydana gelen iş kazalarına ait ölçütler.

\section{Sonuç ve Öneriler}

Ormancılık sektörü verilerine bakıldığında iş kazaları ölçütleri açısından zamansal bir artış eğilimi olduğu görülmektedir. Ancak çalışan işçi sayısı ve ölümlü olmayan kaza sayıları açısından değerlendirildiğinde; ormancılık sektöründe en düşük işçi sayısının görüldüğü 2019 yılındaki ölümlü olmayan iş kazası sayısının; çalışan işçi sayısının en fazla görüldüğü 2015 senesindeki iş kazası sayısından bile daha yüksek olduğu tespit edilmiştir. Ölümlü iş kazası sayısında ise durağanlık söz konusudur. Her iki durumun da orman işçilerinin iş güvenliği eğitimlerinden kaynaklandığı düşünülmektedir (Tablo 1).

İş kazası değerlendirmelerinde işçi ve iş kazası sayılarına ait verilerin sağlıklı işlenmesinin büyük önemi vardır. Ülkemizde, iş kazaları sayıları yasal zorunluluk nedeniyle SGK'ya bildirilmektedir. İşçi sayıları da işverenlerin sigorta bildirgelerinden elde edilmektedir. Ancak bir yıl içinde çalışan işçi sayılarında değişkenlik olması, mevsimlik işçi çalışması, izin veya rapor kullanımı ve çalışma sürelerindeki farklılıklar yıllık işçi sayısının saptanmasını zorlaştırmaktadır. Müngen (1993)'e göre, ülkeler veya sektörler düzeyinde toplam çalışma saati sağlıklı biçimde saptanamadığından, ülkeler veya sektörler arasında karşılaştırma yapılırken, KF yerine KSO ölçütüyle değerlendirmeler yapılması önerilmiştir.

Ormancılık sektöründe çalışan işçiler diğer iş sektörlerinde çalışan işçilerden farklı olarak;

- Her türlü klimatik etkenden doğrudan etkilenmekte, ekstrem hava koşullarına maruz kalabilmekte,

- Topografyadaki ani iniş çıkışlar, yoğun bitki örtüsü, yer örtücü ve sarılıcı bitkiler ve/veya ağaç dalları gibi farklı sebeplerden dolayı hareket kabiliyetinde zorluklar meydana gelebilmekte,

- Farklı çalışma şekilleri, yüksek rakımda çalışma, ağır iş koşulları, beslenme-barınma kalitesinin yetersiz, sağlıksız ve düzensiz olması, olumsuz psikososyal şartlar, kişisel koruyucu donanımların yeterli olmaması ve düşük derecede mekanizasyon kullanımı gibi olumsuz iş koşullarında çalışma zorunluluğu, 
- İşletme ve çalışanlar açısından yeterli bir iş güvenliği kültürünün mevcut olmaması, sertifikalandırma konusunda istenilen seviyeye halihazırda ulaşılamamış olunması,

- Çoğunlukla mevcut çalışma alanlarının telekomünikasyon ağı dışında olması nedeniyle olası kaza durumlarında, haberleşme sıkıntıları ve ilk müdahale ekiplerine haber verme sıkıntıları ortaya çıkabilmektedir.

Söz konusu koşullar nedeniyle, ormancılık sektöründe çalışan işçilerin, ilgili yönetmeliklerde belirtilmiş olan iş güvenliği ve sağlığı eğitimi ve yaralanmalara karşı ilk yardım eğitimini alması ayrıca acil haberleşme gereksinimleri için telefona alternatif olarak telsiz bulundurulması, acil müdahale gereksinimi durumunda kaza yerine ulaşabilmek için Global Positioning System (GPS) bilgilerinin günlük olarak paylaşılması gerekmektedir.

Ayrıca ormancılık sektörü de çalışma alanları açısından farklı iş faaliyetleri içermektedir. Bu nedenle meydana gelen her iş kazasının hangi ormancılık iş kolunda meydana geldiğinin doğru olarak bildirilmesi gerekli önlemlerin alınması açısından önem arz etmektedir. Bu sayede, kaza sayısını en aza indirmek için gerek yeni tedbirler gerekse daha kapsamlı iş güvenliği ve sağlığına dair eğitimlerin hangi ormancılık iş kalemlerinde iyileştirilmesi veya arttırılması gerektiği daha rasyonel bir gereklilik olarak değerlendirilmiştir.

\section{Teşekkür}

Makaleyi geliştirmemize katkı sağlayan yapıcı yorumlar için hakemlere ve editöre teşekkür ederiz.

\section{Kaynaklar}

1. Acar, H., Şentürk, N. (1999). Artvin yöresindeki orman işçilerinde işçi sağlığı üzerine bir araştırma. İstanbul Üniversitesi Orman Fakültesi Dergisi, 49(1), 25-40.

2. Allman, M., Jankovský, M., Allmanová, Z., Ferenčík, M., Messingerová, V., Vlčková, M., Stoilov, S. (2017). Work accidents during cable yarding operations in Central Europe 2006-2014. Forest Systems, 26(1), $1-8$.

3. Bentley, T., Parker, R., Ashby, L. (2005). Understanding felling safety in the New Zealand forest industry. Applied Ergonomics, 36 (2), 165-175.

4. Ceylan, H. (2012). Analysis of occupational accidents according to the sectors in Turkey. Gazi University Journal of Science, 25(4), 909-918.

5. Ceylan, H. (2014). Türkiye'de inşaat sektöründe meydana gelen iş kazalarının analizi. International Journal of Engineering Research and Development, 6(1), 1-6.

6. Ceylan, H. (2015). Analysis of fatal occupational accidents in Turkey for the year 2013. Journal of Multidisciplinary Engineering Science and Technology, 2(3), 314-320.

7. Cividino, S. R. S., Maroncelli, E., Vello, M., Gubiani, R., Snidero, I., Pergher, G., Colantoni, A. (2012). Accident analysis during the chainsaw use: prevention and protection measures to reduce injuries. In Proceedings of the International Conference RAGUSA SHWA.

8. Enez, K., Topbas, M., Acar, H. H. (2014). An evaluation of the occupational accidents among logging workers within the boundaries of Trabzon Forestry Directorate, Turkey. International Journal of Industrial Ergonomics, 44(5), 621-628.

9. Eurostat (2020). https://ec.europa.eu/eurostat/statistics-explained/index.php/Forests,_forestry_and_logging (06.08.2020).

10. Güllüoğlu, E. N., Taçkın, E. (2018). Türkiye tekstil sektöründe istihdam ve iş kazalarının analizi. Journal of Textiles \& Engineers/Tekstil ve Mühendis, 25(112), 344-354

11. Güllüoğlu, E. N., Güllüoğlu, A. N. (2019). Türkiye'de metal sektöründe meydana gelen iş kazalarının analizi. International Journal of Advances in Engineering and Pure Sciences, 31(1), 70-82.

12. Gumus, S., Okan, S.U., Hatay, T.Y. (2019). Analysis of work accidents in wood harvesting: a case study of the East Black Sea region. Forestist, 70(1), 1-7.

13. ILO (2020a). International Labour Organization. https://www.ilo.org/global/topics/safety-and-health-atwork/lang--en/index.htm, (10.08.2020).

14. ILO (2020b). International Labour Organization.

15. https://www.ilo.org/global/industries-and-sectors/forestry-wood-pulp-and-paper/lang--en/index.htm, (10.08.2020).

16. Klun, J., Medved, M. (2007). Fatal accidents in forestry in some European countries. Croatian Journal of Forest Engineering: Journal for Theory and Application of Forestry Engineering, 28(1), 55-62. 
17. Kogler, R., Quendler, E., Boxberger, J. (2016). Occupational accidents with agricultural machinery in Austria. Journal of Agromedicine, 21(1), 61-70.

18. Lilley, R., Feyer, A. M., Kirk, P., Gander, P. (2002). A survey of forest workers in New Zealand: Do hours of work, rest, and recovery play a role in accidents and injury?. Journal of Safety Research, 33(1), 53-71.

19. Müngen, U. (1993). Türkiye'de inşaat iş kazalarının analizi ve iş güvenliğinin sorunu, Doktora Tezi, İTÜ, Fen Bilimleri Enstitüsü, İstanbul.

20. Özdemir, İ. (2019). İş Sağlığı ve Güvenliği Kavram ve Kurallarının Gelişimi. E. A. Oral (Ed.). İş Sağlığı ve Güvenliği içinde. Erzurum: Atatürk Üniversitesi Açıköğretim Fakültesi Yayını, 4-21.

21. Polatoğlu, G., Sincar, S. (1999). Avrupa'da iş sağlığı ve güvenliği'nin ortaya çıkması ve Türkiye’deki uygulamalar1. Atatürk Dergisi, 7(2), 71-95.

22. Rhee, K. Y., Choe, S. W., Kim, Y. S., Koo, K. H. (2013). The trend of occupational injuries in Korea from 2001 to 2010. Safety and Health at Work, 4(1), 63-70.

23. Robb, W., Cocking, J. (2014). Review of European chainsaw fatalities, accidents and trends. Arboricultural Journal: The International Journal of Urban Forestry, 36(2), 103-126.

24. Robert, K., Elisabeth, Q., Josef, B. (2015). Analysis of occupational accidents with agricultural machinery in the period 2008-2010 in Austria. Safety Science, 72, 319-328.

25. SGK (2019). SGK İstatistik Y1llıkları, http://www.sgk.gov.tr/wps/portal/sgk/tr/kurumsal/istatistik/sgk_istatistik_yilliklari (10.08.2020)

26. Tsioras, P. A., Rottensteiner, C., Stampfer, K. (2011). Analysis of accidents during cable yarding operations in Austria 1998-2008. Croatian Journal of Forest Engineering: Journal for Theory and Application of Forestry Engineering, 32(2), 549-560.

27. Yüksel, B. (2017). Çalışma ilişkilerine yönelik ilk düzenleme: dilaver paşa nizamnamesi ve çalışma hayatına

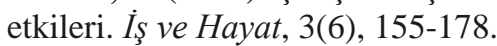

